\title{
Clinical Trial Notes
}

\section{Oncology}

\section{HER2/neu May Not Be an Interesting Target in Biliary Cancers: Results of an Early Phase II Study with Lapatinib}

\author{
Joshua Peck ${ }^{a} \quad$ Lai Wei $^{a} \quad$ Mark Zalupski $^{b} \quad$ Bert O’Neil ${ }^{\mathrm{c}} \quad$ Miguel Villalona Calero $^{\mathrm{a}}$ \\ Tanios Bekaii-Saab ${ }^{a}$ \\ aThe Ohio State University Comprehensive Cancer Center, James Cancer Hospital and Solove Research Institute, \\ Columbus, Ohio, b University of Michigan, Ann Arbor, Mich., and ' University of North Carolina, Raleigh, N.C., USA
}

\section{Key Words}

Biliary cancer $\cdot$ Lapatinib $\cdot$ Epidermal growth factor receptor $\cdot$ HER2/neu

\begin{abstract}
Purpose: Biliary cancers (BCs) respond poorly to chemotherapy. Lapatinib is a dual inhibitor of epidermal growth factor receptor (EGFR) and HER2/neu, both implicated in cholangiocarcinogenesis. This trial was designed to determine the safety and efficacy of lapatinib in BC. Methods: A Fleming phase II design with a single stage of 25 patients was used. The dose of lapatinib was $1,500 \mathrm{mg} /$ day administered orally in 28-day cycles. Tumor and blood specimens were analyzed for expression of HER2/neu and EGFR. Results: Nine patients with $B C$ enrolled in this study. The study was terminated early because of futility. The most common toxicities were nausea and fatigue $(78 \%)$ and diarrhea $(67 \%)$. No responses were observed. Of 8 evaluable patients, 4 (50\%) had stable disease. Median progression-free survival was 2.6 months (95\% Cl 1.6-4.4) and median overall survival was 5.1 months (95\% $\mathrm{Cl}$ 2.0-16.5). No somatic mutations in EGFR (exons 18-21) or HER2/neu were found. We did not find evidence of HER2
\end{abstract}

overexpression. Conclusions: Lapatinib is well tolerated but failed to show activity as a single agent in treating patients with BC. Despite the small patient population, our study is consistent with previous findings, suggesting that targeting HER2/neu does not appear to be an effective therapy for BC.

Copyright $\odot 2012$ S. Karger AG, Basel

\section{Introduction}

Bile duct cancers, which include cholangiocarcinoma and gallbladder cancers, have an incidence of $>14,000$ new cases diagnosed per year in the US [1]. The current standard of care for patients with advanced biliary cancer (BC) consists of the combination of gemcitabine and cisplatin based on a recent study that showed superior outcome over gemcitabine alone [2]. However, the survival for advanced BC rarely exceeds 1 year and the prognosis is universally poor [3]. This has led to a search for molecular targets for therapy.

Potential targets for anticancer therapy in BC included epidermal growth factor receptor (EGFR) and HER2/neu (EGFR2 or ERBB2), both thought to be overexpressed in

\section{KARGER}

Fax +4161306 1234

E-Mail karger@karger.ch

www.karger.com
(C) 2012 S. Karger AG, Basel

0030-2414/12/0823-0175\$38.00/0

Accessible online at:

www.karger.com/ocl
Tanios Bekaii-Saab, MD

The Ohio State University, A454 Starling Loving Hall

320 West 10th Avenue

Columbus, OH 43206 (USA)

E-Mail Tanios.Bekaii-Saab@osumc.edu 
$\mathrm{BC}[4,5]$ and directly implicated in cholangiocarcinogenesis [6-9]. The role of EGFR inhibition was considered significant based on a phase II study, suggesting that erlotinib, an oral tyrosine kinase EGFR inhibitor, had interesting activity in BC [5].

Lapatinib is a dual inhibitor of EGFR and HER2/neu and acts by docking to the ATP-binding site of the two receptors $[10,11]$. In early clinical studies, lapatinib was well tolerated with preliminary evidence of anti-tumor activity. It is currently approved for the treatment of breast cancer [12].

Given that both EGFR and HER2/neu contribute to the behavior of $\mathrm{BC}$, we hypothesized that a dual inhibitor blocking both targets would have a significant therapeutic advantage over compounds that inhibit one receptor. Given these observations, we conducted and report here a phase II study to evaluate the efficacy and tolerability of single-agent lapatinib in patients with advanced BC.

\section{Methods}

Eligible patients were required to have histologically confirmed unresectable advanced BC and measurable disease according to the Response Evaluation Criteria in Solid Tumors (RECIST) [13], as well as $\leq 1$ prior systemic anticancer therapy. Patients with prior cryotherapy, radiofrequency ablation, ethanol injection, transarterial chemoembolization or photodynamic therapy were eligible provided that $>6$ weeks since therapy have passed and indicator lesion(s) were outside the area of prior treatment; if the only indicator lesion was inside the prior treatment area, a clear evidence of disease progression was demonstrated. Prior radiation therapy with or without the use of a fluoropyrimidine as a radiosensitizer was allowed in the study if $>12$ weeks have elapsed since therapy. Additional criteria included a life expectancy $\geq 12$ weeks, an Eastern Cooperative Oncology Group performance status $<2$ and the ability to take and absorb oral medications. Patients were required to have normal organ function. Exclusion criteria included patients with prior treatment with EGFR inhibitors, $>450 \mathrm{mg} / \mathrm{m}^{2}$ doxorubicin (given the potential with lapatinib for additional cardiotoxicity, a class effect toxicity seen with HER2/neu inhibitors), major surgery occurring within 3 weeks prior to the planned starting date, brain metastases, history of malignancy other than $\mathrm{BC}$ within the previous 3 years except for adequately treated basal cell carcinoma, squamous cell cancer, or carcinoma of the cervix, uncontrolled intercurrent illness, pregnancy, HIV infection, and concomitant requirement for medication classified as CYP3A4 inducer or inhibitor.

\section{Study Design}

This was a National Cancer Institute (NCI)-sponsored phase II, open-label, multicenter trial led by the Ohio State University with the participation of the University of Michigan, Virginia Commonwealth University, H. Lee Moffitt Cancer Center, and the University of North Carolina. Lapatinib was provided by the

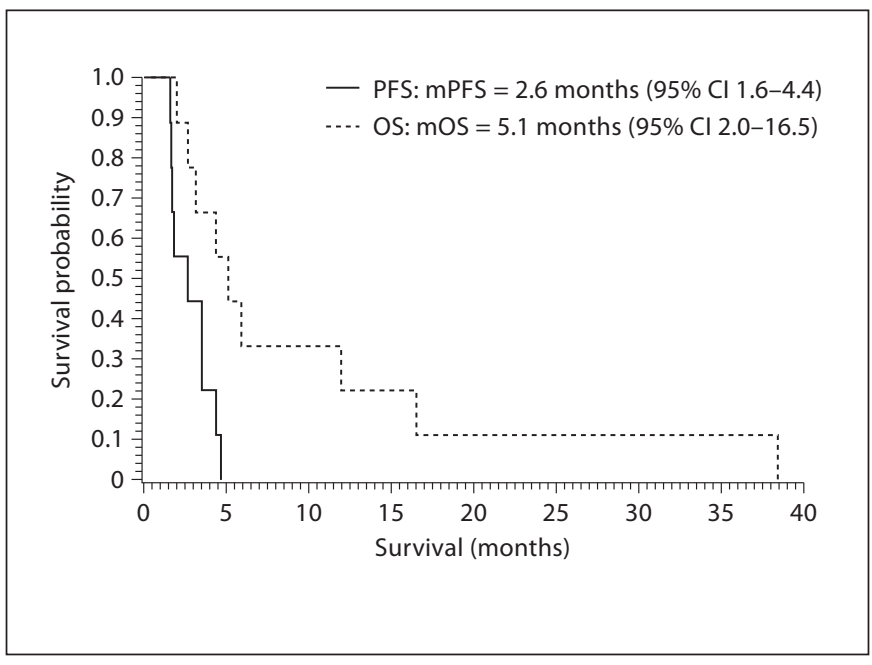

Fig. 1. Kaplan-Meier plots for OS and PFS.

NCI/Cancer Therapy Evaluation Program. The primary endpoint of this trial is the proportion of patients demonstrating objective response [partial response (PR) + complete response (CR)] as defined by the RECIST response criteria. We used a Fleming phase II design resulting in a single stage of 25 patients. If $\geq 5$ of the 25 patients demonstrate a PR or a CR, the agent will be recommended for further study in this patient population $(a=0.10 ; b=0.10$; $\mathrm{p}_{0}=0.1 ; \mathrm{p}_{1}=0.3$ ). Tissue and blood samples were required for all patients. Secondary objectives included evaluation of toxicity, overall survival (OS), assessment of mutations of EGFR and HER2/neu genes and measurement of expression of proteins in signaling pathways relevant to lapatinib including HER2/neu.

\section{Lapatinib Administration and Dose Modifications}

The starting dose and schedule of lapatinib was $1,500 \mathrm{mg} /$ day orally without interruption in 28 -day cycles. There were three levels of dose reductions planned (1,250, 1,000 and $750 \mathrm{mg} /$ day) with patients taken off the study if they needed additional dose reductions.

\section{Assessment of Response and Toxicity}

Radiological assessment was done by CT or MRI (as long as the same consistent measure was used serially) every 8 weeks, and responses were measured according to the RECIST criteria. Toxicities were defined by the NCI-CTCAE, version 3.0.

\section{Correlative Studies}

Either fresh or paraffin-embedded tissue from tumor blocks and adjacent normal tissue was required from patients before enrolling in this study. One blood sample was obtained before patients enrolled in the study with a goal to examine germline mutations.

Methods for assessment of HER2/neu and enumeration of chromosome 17 (CEP17) by fluorescence in situ hybridization, HER2/neu and EGFR mutation screening were previously published by our group $[14,15]$. 
Table 1. Patient demographics and characteristics

\begin{tabular}{llc}
\hline Sex & Male & 3 \\
& Female & 6 \\
\hline Age, years & Median & 61 \\
& Range & $31-83$ \\
\hline Race/ethnicity & White & 9 \\
\hline Prior treatments & X-ray & 1 \\
& Surgery & 5 \\
Sites of & Chemotherapy & 3 \\
metastasis & Lymph nodes & 6 \\
& Lungs & 3 \\
& Hepatic metastases & 3 \\
& Porta hepatis & 2 \\
& Long bones & 2 \\
& Spine & 2 \\
& Abdomen & 1 \\
& Ribs & 1 \\
& Hepatorenal fossa & 1 \\
of treatment & Chest wall & 1 \\
\hline
\end{tabular}

$\mathrm{ULN}=$ Upper limit of normal $(37 \mathrm{U} / \mathrm{ml})$.
Table 2. Toxicities $(n=9)$

\begin{tabular}{|c|c|c|c|c|}
\hline Toxicity & All toxicities & Grade 1 & Grade 2 & Grade 3 \\
\hline Diarrhea & 11 & 8 & 2 & 1 \\
\hline Fatigue & 9 & 3 & 6 & 0 \\
\hline Nausea & 9 & 4 & 5 & 0 \\
\hline Abdominal pain & 3 & 0 & 3 & 0 \\
\hline Anorexia & 4 & 0 & 4 & 0 \\
\hline Dizziness & 3 & 3 & 0 & 0 \\
\hline Rash & 3 & 3 & 0 & 0 \\
\hline Constipation & 2 & 0 & 2 & 0 \\
\hline Hypercalcemia & 2 & 1 & 1 & 0 \\
\hline Joint pain & 2 & 2 & 0 & 0 \\
\hline Neck pain & 2 & 2 & 0 & 0 \\
\hline Agitation & 1 & 1 & 0 & 0 \\
\hline ALT & 1 & 1 & 0 & 0 \\
\hline AST & 1 & 1 & 0 & 0 \\
\hline Bloating & 1 & 1 & 0 & 0 \\
\hline Chest pain & 1 & 1 & 0 & 0 \\
\hline Dysgeusia & 1 & 1 & 0 & 0 \\
\hline Emesis & 1 & 1 & 0 & 0 \\
\hline Fracture & 1 & 0 & 0 & 1 \\
\hline Generalized pain & 1 & 0 & 1 & 0 \\
\hline Headache & 1 & 1 & 0 & 0 \\
\hline Hypoalbuminemia & 1 & 1 & 0 & 0 \\
\hline Hypokalemia & 1 & 0 & 1 & 0 \\
\hline Hyponatremia & 1 & 1 & 0 & 0 \\
\hline \multicolumn{5}{|l|}{ Partial gastric outlet } \\
\hline obstruction & 1 & 0 & 1 & 0 \\
\hline
\end{tabular}

There were no grade 4 toxicities. ALT = Alanine aminotransferase; AST = aspartate aminotransferase.

\section{Treatment Toxicity}

Only 1 patient (11\%) required dose reduction. One patient had to stop the drug secondary to fatigue (grade 2 toxicity). The most common toxicities included nausea and fatigue (both 78\%) and diarrhea (67\%). Only one grade 3 toxicity (diarrhea) was noted. There were no grade 4 toxicities. All toxicities were reversible (table 2).

\section{Treatment Efficacy}

A median of 3.4 cycles was administered (range 1-5) with a median follow-up time of 69 days. There were no objective responses. Out of 8 evaluable patients, only 4 patients (50\%) had stable disease and another $4(50 \%)$ had progressive disease as their best response. Three patients (33\%) had a $>20 \%$ decrease in their CA19-9 baseline levels. The mean PFS (mPFS) was 2.6 months (95\% CI 1.64.4) and the mean OS (mOS) was 5.1 months (95\% CI 2.0-16.5) (fig. 1). 


\section{Biological Markers}

Tissue and blood specimens were available for all patients. No somatic mutations in EGFR (exons 18-21) were found. Additionally, we did not find evidence of HER2/ neu somatic mutations. The HER2/neu copy number was neither elevated per fluorescence in situ hybridization nor was HER2/neu protein expression increased per immunohistochemistry.

\section{Discussion}

$\mathrm{BC}$ represents one of the most challenging cancers. The rationale for this study was based on the demonstration of a role for EGFR and HER2/neu signaling pathways in the carcinogenesis of $\mathrm{BC}$.

Results from our analysis reveal no activity for lapatinib as a single agent in treating patients with advanced $\mathrm{BC}$ based on the lack of objective response in the first 9 patients. There was biochemical (CA19-9) evidence of response in 3 patients. The reported $\mathrm{mPFS}$ and mOS were short and not clinically meaningful. Despite the small number of patients included in our analysis, our findings are very consistent with those of a similar study with $17 \mathrm{BC}$ patients that was terminated early because of futility [16].

Retrospective studies report HER2/neu overexpression ranging from 5 to $76 \%$ in cholangiocarcinoma [ 4 , 16-18], but our prospective correlative analysis reveals no overexpression of HER2/neu. The discrepancy in the reported rates could possibly be attributed to different phe- notypic subtypes. Of course, this conclusion is limited by the small sample size of our study, although arguably if present, HER2/neu overexpression is unlikely to be significant. Consistent with other reports $[15,16]$ and our previously published data [14], we also found no evidence of activating mutations in EGFR or HER2/neu.

Despite the initial enthusiasm for targeting HER2/neu in addition to EGFR in BC, two studies with lapatinib (including ours) were terminated early because of lack of activity. As such, HER2/neu inhibition is not worth pursuing further in advanced BC. Lapatinib has likely weak EGFR activity, and EGFR remains an interesting target given encouraging results from a previous study [5]. Understanding the molecular and genetic mechanisms of $\mathrm{BC}$ is essential to improve the outcome of patients with this deadly disease. Several targets including MEK [19], EGFR [5] and vascular endothelial growth factor [20] remain interesting to pursue, given evidence of preliminary clinical activity.

\section{Ethical Standards}

The trial protocol has been approved by an ethical committee and thus meets the standards of the Declaration of Helsinki in its revised version and its amendments [21].

\section{Disclosure Statement}

The authors declare that they have no conflict of interest.

\section{References}

1 Jemal A, Siegel R, Xu J, Ward E: Cancer statistics. CA Cancer J Clin 2010;60:277-300.

-2 Valle J, Wasan H, Palmer DH, Cunningham D, Anthoney A, Maraveyas A, Madhusudan S, Iveson T, Hughes S, Pereira SP, Roughton $\mathrm{M}$, Bridgewater J: Cisplatin plus gemcitabine versus gemcitabine for biliary tract cancer. $\mathrm{N}$ Engl J Med 2010;362:1273-1281.

3 Schottenfeld D, Fraumeni J: Cancer Epidemiology and Prevention, ed 3. New York, Oxford University Press, 2006.

4 Pignochino Y, Sarotto I, Peraldo-Neia C, Penachioni J, Cavalloni G, Migliardi G, Casorzo L, Chiorino G, Risio M, Bardelli A, Aglietta M, Leone F: Targeting EGFR/HER2 pathways enhances the antiproliferative effect of gemcitabine in biliary tract and gallbladder carcinomas. BMC Cancer 2010;10: 631.
5 Philip PA, Mahoney MR, Allmer C, Thomas J, Pitot HC, Kim G, Donehower RC, Fitch T, Picus J, Erlichman C: Phase II study of erlotinib (OSI-774) in patients with advanced hepatocellular cancer. J Clin Oncol 2005;23: 6657-6663.

6 Lee SC, Lim SG, Soo R, Hsieh WS, Guo JY, Putti T, Tao Q, Soong R, Goh BC: Lack of somatic mutations in EGFR tyrosine kinase domain in hepatocellular and nasopharyngeal carcinoma. Pharmacogenet Genom 2006;16:73-74.

7 Yoon J, Gwak G, Lee H, Bronk SF, Werneburg NW, Gores GJ: Enhanced epidermal growth factor receptor activation in human cholangiocarcinoma cells. J Hepatol 2004; 41:808-814.
${ }_{8}$ Werneburg NW, Yoon J, Higuchi H, Gores GJ: Bile acids activate EGF receptor via a TGF- $\alpha$-dependent mechanism in human cholangiocyte cell lines. Am J Physiol Gastrointest Liver Physiol 2003;285:G31-G36.

-9 Nakazawa K, Dobashi Y, Suzuki S, Fujii H, Takeda Y, Ooi A: Amplification and overexpression of c-erbB-2, epidermal growth factor receptor, and c-met in biliary tract cancers. J Pathol 2005;206:356-365.

10 Rusnak DW, Lackey K, Affleck K, Wood ER, Alligood KJ, Rhodes N, Keith BR, Murray DM, Knight WB, Mullin RJ, Gilmer TM: The effects of the novel, reversible epidermal growth factor receptor/ErbB-2 tyrosine kinase inhibitor, GW2016, on the growth of human normal and tumor-derived cell lines in vitro and in vivo. Mol Cancer Ther 2001; 1:85-94. 
11 Shewchuk L, Hassell A, Wisely B, Rocque W, Holmes W, Veal J, Kuype LF: Binding mode of the 4-anilinoquinazoline class of protein kinase inhibitor: X-ray crystallographic studies of 4 -anilinoquinazolines bound to cyclin-dependent kinase 2 and p38 kinase. J Med Chem 2000;43:133-138.

12 Geyer CE, Forster J, Lindquist D, Chan S, Romieu CG, Pienkowski T, Jagiello-Gruszfeld A, Crown J, Chan A, Kaufman B, Skarlos D, Campone M, Davidson N, Berger M, Oliva C, Rubin SD, Stein S, Cameron D: Lapatinib plus capecitabine for HER2-positive advanced breast cancer. N Engl J Med 2006; 355:2733-2743.

13 Therasse P, Arbuck SG, Eisenhauer EA, Wanders J, Kaplan RS, Rubinstein L, Verweij J, Van Glabbeke M, van Oosterom AT, Christian MC, Gwyther SG: New guidelines to evaluate the response to treatment in solid tumors. J Natl Cancer Inst 2000;92:205-216.
14 Bekaii-Saab T, Markowitz J, Prescott N, Sadee W, Heerema N, Wei L, Dai Z, Papp A, Campbell A, Culler K, Balint C, O’Neil B, Lee R, Zalupski M, Dancey J, Chen H, Grever M, Eng C, Villalona-Calero M: A multi-institutional phase II study of the efficacy and tolerability of lapatinib in patients with advanced hepatocellular carcinomas. Clin Cancer Res 2009;15:5895-5901.

15 Bekaii-Saab T, Williams N, Plass C, Calero $\mathrm{M}$, Eng C: A novel mutation in the tyrosine kinase domain of ERBB2 in hepatocellular carcinoma. BMC Cancer 2006;6:278.

16 Ramanathan RK, Belani CP, Singh DA, Tanaka M, Lenz HJ, Yen Y, Kindler HL, Iqbal S, Longmate J, Mack PC, Lurje G, GandourEdwards R, Dancey J, Gandara DR: A phase II study of lapatinib in patients with advanced biliary tree and hepatocellular cancer. Cancer Chemother Pharmacol 2009;64: 777-783.

17 Harder J, Waiz O, Otto F, Geissler M, Olschewski M, Weinhold B, Blum HE, Schmitt-Graeff A, Opitz OG: EGFR and HER2 expression in advanced biliary tract cancer. World J Gastroenterol 2009;15:45114517.
8 Ukita Y, Kato M, Terada T: Gene amplification and mRNA and protein overexpression of c-erbB-2 (HER-2/neu) in human intrahepatic cholangiocarcinoma as detected by fluorescence in situ hybridization, in situ hybridization, and immunohistochemistry. J Hepatol 2002;36:780-785.

19 Bekaii-Saab T, Phelps MA, Li X, Saji M, Goff L, Kauh JSW, O’Neil BH, Balsom S, Balint C, Liersemann R, Vasko VV, Bloomston M, Marsh W, Doyle LA, Ellison G, Grever M, Ringel MD, Villalona-Calero MA: Multi-institutional phase II study of selumetinib in patients with metastatic biliary cancers. J Clin Oncol 2011;29:2357-2363.

20 Zhu AX, Hezel AF: Development of molecularly targeted therapies in biliary tract cancers: reassessing the challenges and opportunities. Hepatology 2011;53:695-704.

21 Rennie D: Disclosure to the reader of institutional review board approval and informed consent. J Am Med Assoc 1997;277:922-923. 